\title{
Review
}

\section{Anaesthetics of existence: Essays on experience at the edge}

\author{
Cressida Heyes \\ Duke University Press, Durham, 2020, vii+180pp., ISBN 9781478007814
}

Contemporary Political Theory (2021) 20, S168-S171. https://doi.org/10.1057/s41296020-00441-1; published online 17 September 2020

Anaesthetics of Existence is a boldly innovative sequel to Cressida Heyes' earlier foray into the question of bodily agency. Heyes' Self-Transformations: Foucault, Ethics, and Normalized Bodies (2007) delivered a Foucauldian analysis of somatic normalization. Heyes argued that bodies are inescapably 'constituted through disciplinary power' (2007, p. 8); however, within this disciplinary frame, some bodily practices may offer a challenge to normalization from within. In particular, the book ended with the suggestion that Michel Foucault's late work on the aesthetics of existence — an ethical ethos that implies 'making oneself as art' (2007, p. 2) - offered valuable insights for rethinking our agentive possibilities as embodied selves that are 'located within a web of sometimes contradictory norms' (2007, p. 117). The project of '[making] ourselves differently' (2007, p. 135), Heyes concluded, requires that we recognize the force of normalizing powers but still critically imagine 'possibilities for a life of greater embodied freedom' (2007, p. 136).

Anaesthetics of Existence picks up almost exactly where Self-Transformations left off, with a discussion of Foucault's late ethics. And yet, Anaesthetics of Existence is interestingly at odds with-but not unrelated to-the earlier book's focus on the ethical task of self-transformation. Whereas Self-Transformations examined the tension between normalizing forces and embodied resistance, this new work broaches the question of normalization through the analysis of more 'diffuse, drifting, unpunctuated and unproductive' (p. 22) forms of existence and modes of experiencing. Perhaps the best way to understand this point is by turning to the anecdote which opens the book. Heyes tells the story of attending a Foucault conference and of dozily mishearing a speaker repeatedly referring to 'anaesthetics of existence' (p. 2). The speaker, Heyes later realized, was simply speaking too fast, thereby leading Heyes to miss that she was, in fact, referring to the muchdiscussed Foucauldian concept of 'an aesthetics of existence' (p. 2). However, Heyes interprets this 'productive mishearing' (p. 2) as a provocation. 'The ethical work of the aesthetics of existence, with its implication of making oneself as art',

(C) 2020 Springer Nature Limited. 1470-8914 Contemporary Political Theory Vol. 20, S4, S168-S171 
she writes, 'in that moment felt grand and really tiring' (p. 2). In fact, the lived experience of contemporary neoliberal subjects itself can be utterly 'exhausting, ego-driven, obsessed with irrelevant choices, and abusively self-disciplining, committed to the fantasy of organizing and rationalizing a life of freedom in political contexts in which freedom is systematically denied' (p. 7). For Heyes, the vicious self-disciplining that is required of neoliberal subjects sheds new light on the ideal of aesthetic self-transformation.

Under contemporary conditions, the ethical desire for an 'exemplary, critical, beautiful life' (p. 6) is both 'very privileged and very depleting' (p. 2). Heyes shows that the pressure of making oneself as a subject and of demonstrating personhood generates a complex set of affects. These affects are routinely sublimated through 'compulsive, numbing, addictive activities that render working life under neoliberalism more tolerable' (p. 7), from the stigmatized consumption of recreational opiates to the seemingly innocuous pleasures of cheap wine marketed for white, middle-class, multi-tasking mothers. In other words, faced with rationalized expectations of self-discipline and productivity, the contemporary subject of neoliberalism 'checks out' from time to time. Heyes coins the notion of 'anaesthetic time' (p. 105) to describe the numbing of perception, sensation, and future-oriented action characteristic of activities that halt the linear progression of normative, 'postdisciplinary time' (p. 21). 'Anaesthetic temporality ... is a sensical response to postdisciplinary time' (22); it is the shadow and necessary counterpart of the 'linearly protensive' (p. 99) unfolding of postdisciplinary time. Phenomenologically, anaesthetic time warps the protentional (or futural) orientation of time. In disrupting the flow of 'normal' temporality as it has been analyzed by phenomenologists, anaesthetic time reveals how social and political structures are folded into our experience and contribute to shaping it. Against the grain of an ethics driven by the aesthetic crafting of the self, the anaesthetics of existence that Heyes analyzes concerns a sort of unraveling, a slowing down of time that fragments the unmarked ideal of an exclusively autonomous, sovereign, and voluntary self. In its place, Heyes finds a 'chiasmic folding of subjectivity as constituted and constituting' (p. 142), a subject both 'exceeding the background experience of [its] cultural moment' (p. 137) and emerging against this background itself.

Anaesthetics of Existence makes three major intellectual contributions to the fields of phenomenology, feminist philosophy, and social and political theory. First, methodologically, Heyes provides a new foundation for a philosophy of experience that bridges Foucauldian genealogy and feminist phenomenology, thus resolving many long-standing scholarly tensions between these approaches. Heyes' thematic explorations throughout the book build on this hybrid method. Secondly, her analyses of sexual violence against unconscious victims (chapter 2), work and life under postdisciplinary time (chapter 3), everyday anaesthetics (chapter 4), and the pain and ecstasy of childbirth (chapter 5) challenge traditional understandings of

(C) 2020 Springer Nature Limited. 1470-8914 Contemporary Political Theory Vol. 20, S4, S168-S171 S169 
the category of 'experience' itself. More than an explicit 'underdoing readily available for ... interrogation' (p. 20), experience is revealed to be a 'normative category' (p. 24) with tendentious edges. By tracing these edges, Heyes asks both what counts as an experience and whose experiences matter. Finally, Heyes' study of experience pushes back against the primacy of active agency for political theory. Postdisciplinary time is 'relentlessly depleting' (p. 22); it consistently 'supports productive action and marginalizes inaction' (p. 10). In response, and through various registers of passivity, refusal, and inaction, anaesthetic 'withdrawals from sensory experience' (p. 6) can function as sites of political dissent. This is not to say that inaction is inherently resistant or liberatory, as Heyes' description of the complex harms of rape while unconscious clearly indicates. However, the normative assumption that 'action is productive, and to be productive is to be ethically valuable' (p. 144) harmfully nullifies and silences 'sensations and undergoings' (p. 29) that do not fit this normalizing frame, including violations of bodily integrity and anonymity in rape.

In closing, I want to offer a few brief remarks about Heyes' discussion of the category of experience. Heyes' exegetical and critical analysis of 'experience' as a key notion for phenomenology and feminist theory is pivotal; it will undoubtedly shape future discussions within and across these traditions. For decades, feminists have rightly criticized the depoliticized conception of experience at the heart of traditional phenomenology. First, traditional phenomenologists have long relied on a putatively universal account of embodied experience that reproduces dominant norms of whiteness, masculinity, and ability. Secondly, experience is always 'formed by a larger context that gives it meaning' (p. 30), and thus it is not 'an origin of political truth' (p. 28). Some have argued that making experience a key vector for feminist theorizing risks obscuring that it is always 'the product of an already-existing politics' (p. 28). Yet, as Heyes argues, the impulse of feminist and critical phenomenology is not irreconcilable with a genealogical approach that critically attends to the constitution of subjectivity through dominant norms. Indeed, Heyes' joint mobilization of phenomenological and genealogical approaches reveals that experience is both partial, contextual, and historicallymediated and lived pre-reflexively by the 'sensing, feeling subject in a range of ways, including through critique' (p. 41). Finally, '[although] there is always the iterative possibility — or even the certainty — that we will fail to grasp some element of our own constitution, the possibility of reflecting on ourselves is real, not least because we do it' (p. 41). The goal, then, is to 'make sense of experience on this intermediary terrain where dominant discourse is in mutual relation with subjective life' (p. 43), noticing how and where they fold into each other and remaining reflexively aware of all that escapes us.

Without a doubt, Heyes' Anaesthetics of Existence is a marvelously written, timely, and exciting book. It is both a scholarly feat-impeccably researched and 
persuasively argued - and a pleasurable read that offers some respite and solace amidst the chaos of postdisciplinary time.

\section{Reference}

Heyes, C. (2007). Self-Transformations: Foucault, Ethics, and Normalized Bodies. Oxford: Oxford University Press.

Publisher's Note Springer Nature remains neutral with regard to jurisdictional claims in published maps and institutional affiliations.

Corinne Lajoie

Pennsylvania State University, State College, PA 16801, USA cv15810@psu.edu 